\title{
In our opinion
}

\author{
G. Roberts, ${ }^{* 1}$ V. S. Lucas, ${ }^{1}$ F. McDonald, ${ }^{1}$ S. Camilleri, ${ }^{2}$ J. Jayaraman, ${ }^{3}$ D. Davies ${ }^{4}$ and K. Moze ${ }^{5}$
}

\section{In brief}

Repudiates the claims made in the column of the News section of the issue of the British Dental Journal in December 2016 published under the auspices of the BDA's Chair of the Education, Ethics and Dental Team Working Group.
Indicates that it is permissible in law to use ionising radiation to create radiographic images of the teeth and jaws to derive clinico-radiographic information about subjects who are not seeking clinical diagnosis or dental treatment.
Repudiates the statements related to consent promulgated by the Chair of the Education, Ethics and Dental Team Working Group. Considerable care is taken by carers and dentists to ensure that a robust consent procedure is followed.
Draws attention to the neglect of issues relating to child protection and safegaurding.

The misleading statements made in the British Dental Journal in the December 2016 issue relating to dental age assessment are assessed for inaccuracies and negligent omission of the issue of Child Protection. It is emphasised that there is a need for the approach of objective knowledge viz. not influenced by personal feelings or opinions in considering and representing facts. The article by the Chair of the Education, Ethics, and Team Working Group implies that unsatisfactory consent procedures are followed. The DARLInG (Dental Age Research London Information Group) have followed a carefully prescribed procedure that fulfils all the requirements of the advice given by the Consent Committee at King's College Hospital. In addition, the active support in the form of independent support workers and lawyers assisted by interpreters is described. The issue of the lawful use of ionising radiation is described with correct information about where this information can be obtained. The seriously misleading statements made by the Chair of the Education, Ethics and Education Working Group are identified. An unacceptable oversight is the failure of the BDA representatives to draw attention to the need for child protection. The potential benefit of dental age estimation in terms of appropriately providing support for asylum seekers is described. The failure of the BDA Ethics group to be up to date with recent research which shows a high level of certainty in assigning age disputed subjects to above (or below) the 18-year threshold is discussed and the importance of this in reliably determining, in an objective way, the age status of asylum seekers. The incorrect and salacious use of the term ' $X$-rated' is highlighted and a formal request for its withdrawal has been made.

\section{'X-rays and X-rated' and 'Agreed, but if ...?'}

The above two headlines appeared in the British Dental Journal, the first in December 2016 and the second in January 2017. They are linked by the theme of age estimation in children and young adults involving exposure of subjects to ionising radiation for the purposes of age estimation. In practice, the dental radiograph

All authors are from the Dental Age Research London Information Group [DARLInG]. 'King's College London; ${ }^{2}$ University of Malta; ${ }^{3}$ Date of Birth Foundation in India; ${ }^{4}$ Member of UK Parliament; ${ }^{5}$ Dental Radiologist in Trinidad ${ }^{*}$ Correspondence to: Graham Roberts Email: graham.roberts101@outlook.com

Refereed Paper. Accepted 26 April 2017 DOI: $10.1038 /$ sj.bdj.2017.537 under consideration is the dental panoramic tomograph (DPT). Other radiographic views may be used but it is the DPT that is used for the majority of dental age estimations (DAE). The British Dental Association, through its chair of the Education, Ethics and Dental Team Working Group expresses its concern regarding the use of radiographs for dental age estimation.

The concern is expressed in several ways. None of the misleading statements withstand objective scrutiny. By objective we mean not influenced by personal feeling or opinions in considering and representing facts. It is helpful to consider the misleading statements in the column by Dr Judith Husband and the Editorial by Dr Stephen Hancocks together as they are linked.

\section{Consent}

The issue of consent has been inappropriately considered by the BDA. The column states that 'It is unlikely that any migrant from Calais would understand the nature of the procedure.' ${ }^{1}$ This concern also relates equally to any other clinically related procedure; many of our patients do not fully understand the nature of the procedure for which consent is sought. It is the duty of the clinician to ensure that adequate explanation about the nature of the procedure and its implications are explained in such a way that the subject understands what is involved and also the implications of the procedure to the subject's future. Dental age estimation is treated with the same thoroughness. It is helpful to reiterate the requirements 
for informed consent ${ }^{2}$ paraphrased here as:

1. Comprehend the relevant information

2. Remember the information

3. Believe it

4. Weigh it in the balance

5. Arrive at a choice.

The process and documentation used to obtain consent for DAE were approved by the Consent Committee at King's College Hospital in 2008. It is this procedure that is followed. In practice, the interests of the subject are protected by the multiple agencies representing these interests.

The BDA are woefully unaware of the process to which migrants are subjected when the claimed age is disputed. Every single migrant is provided with support to help navigate the process of application for asylum. This support includes the appointment of a social worker and a legal adviser, both of whom utilise the services of an interpreter. It is clear the requirements for informed consent are fulfilled perhaps more assiduously than consent for simple dental treatment.

The BDA direct one of their concerns to the issue of whether the migrants 'have someone consent on their behalf.' ${ }^{1}$ This has never happened in our clinics except in the case of children. This aspect of the BDA comment is misplaced. None of the adults have someone else consent for them. This would be illegal except when the adult showed a lack of competence to give consent. In the case of minors, a parent or an adult acting in loco parentis is the person legally charged with the responsibility of providing consent for and on behalf of children in their care. Our interpretation of the statement 'or have someone consent on their behalf', is that the BDA consider it appropriate to remove from social workers their duty to provide appropriate care for children. Are the BDA seriously suggesting that children should be denied this right to have someone act lawfully on their behalf? Since the advent of Gillick Competence, subjects under 16 years of age may give consent for themselves, provided the dental surgeon believes that the conditions listed above are fulfilled.

\section{Adults masquerading as children}

A difficulty for DAE is that the subjects are 'age disputed' - this usually means that an adult looking subject is claiming to be under 18 years old. In practice, the subject's claim of being under 18 years old is regarded as the prevailing circumstance with regard to the acquisition of consent. That is to say the procedures for taking consent from children are followed.

\section{lonising radiation regulations}

The comments relating to the Ionising Radiation (Medical Exposure) Regulations (IR[ME]R) are seriously misleading. It is permitted under the regulations to carry out radiographic examinations for nontherapeutic and non-diagnostic purposes. An example of such an exposure is the use of radiographs to assist in the preparation of medico-legal reports for insurance purposes for which there is no medical indication. ${ }^{3} \mathrm{~A}$ further use of radiographs where there is no benefit to the subject is in ethically approved clinical research. The acquisition of panoramic images for dental age estimation clearly falls within this category. The BDA should retract this misleading advice. The issue of 'the benefit of doing so must outweigh the risk' ${ }^{1}$ is also stated incorrectly. In the context of 'benefit' this must be balanced and should benefit the individual and/or society. Despite this formal guidance which has the status of a legal standing in IR(ME)R, the BDA have given misleading advice.

\section{Influence of the courts}

The establishment of 'Disputed Age Status' leads to the following: A social worker carries out a structured interview to help determine the age of the subject. Where the age of the subject determined from a social worker assessment is different from the 'age' claimed by the asylum seeker the subject becomes 'age disputed'. This has always been a claimed age of less than 18 years (the asylum seeker) against an assessed age of over 18 years (the social worker).

To settle such disputes the social worker responsible may seek a DAE. A formal letter of referral initiates this process. If the client refuses the DAE it is usual for the client to retain the services of a solicitor. Since the Immigration Court ruling in 2016, age disputed subjects may be ordered by the Immigration Court to 'accept the Social Workers Assessment that the subject is over 18 years or undergo a Dental Age Estimation." The DARLInG team still seek the appropriate consent following this directive.

\section{Accuracy}

It is important to know that large reference data sets (RDS) on tooth development exist based on clinical archives of many thousands of DPTs. These RDSs comprise 2,900 UK-Caucasian; 2,322 Southern Chinese (Han); 1,589 Maltese; 1,480 Israeli; and 1,565 Kuwaiti subjects. Others are being added as we write. In terms of providing robust data for DAE, this multi-national archive is unparalleled as a resource for providing reliable data to enable DAE. There are no ethical or consent difficulties in re-using clinical radiographs to construct RDS for estimating the age of children and young adults. All the data are recorded anonymously.

There is one thing that we can agree on: 'No two mouths are alike.' If they were it would be impossible to use the variations in dental development to estimate age. The reference to dental eruption is misplaced. We do not use erupted teeth to estimate age. Instead we use the degree of development discernible on DPTs. ${ }^{5,6}$ Where age disputed subjects look adult we use the threshold assignment method. ${ }^{7,8}$ The accuracy of the threshold assignment is such that the probability that a subject is over 18 years is over $97 \%$ and for many circumstances over $100 \%$. These estimates are derived using the gold standard of chronological age as the comparator. On that basis alone it is reasonable to use DAE to assist social workers to fulfil their responsibility to provide an age estimate for asylum seekers, especially unaccompanied asylumseeking children. How else are the authorities able to conscientiously and properly care for these children while at the same time directing adults claiming to be children towards appropriate adult social care?

It is of note that a small number of subjects who are assessed by the DARLInG team are assigned an age of less than 18 years - a result confirming the subjects own claim.

To claim that 'in fact it is not a very accurate method'1 and to use a relatively recent publication to support this statement is misleading. The publication alluded to indicates that subjects with a mature dentition have a high probability $(\mathrm{P}=0.945[94.5 \%])$ that 18 years has been attained. ${ }^{9}$

It is not clear from the January editorial whether DAE is considered to be 'not a very accurate method' or 'not a very inaccurate method' as published in the internet version and hard copy version respectively. ${ }^{10}$ 
In any event the paper cited does not apply to children but gives very strong support to identifying subjects over 18 years old when the lower third molar is fully developed. ${ }^{9}$

The issue of accuracy is important at two different levels. First in children, the simple average method is used. ${ }^{11}$ The developing teeth are assessed and assigned a tooth development stage according to a well-established scheme. ${ }^{12}$ The reference data related to this, including measures of uncertainty such as the 0th (minimum), 25th, 50th, 75th, and 100th (maximum) percentiles which are then used to give an indication of the average value (the 50th percentile). The uncertainty associated with this average value is given as the inter quartile range (IQR) which contains the middle $50 \%$ of the possible ages of the subject, as well as the full range which contains all the possible ages that the subject could be. This is the summary information reported to the agency requesting the DAE. This approach has been accepted by the Immigration Court.

It is important to be aware that dentists do not make a decision regarding the subject's age. We put before the courts/social/workers/ solicitors our findings based on objective knowledge. It is up to those agencies to determine the subject's age. In practical terms it is helpful to work within the IQR. However, this induces a paradox. The professions dealing with age-disputed asylum seekers usually settle for the age range provided by the DARLInG team. However, in a judicial assessment, where the age of the asylum-seeking age disputed individual is determined, it is not appropriate to settle for other than the 'average' age provided. This is for administrative reasons as National Insurance registration, tax documents, passports and driving licences can only display a specific date of birth.

It is regrettable that no formal research has been carried out to assess, in terms of objective knowledge, the accuracy of these so called holistic assessments. Neither the reliability of the point estimate of age, nor the range of expression of uncertainty has been investigated in a formal way. Such an approach is long overdue. These holistic assessments have been used for over ten years and social workers are no further advanced in the reliability of these holistic approaches for age estimates. It is believed that their estimates 'improve' with experience. How can such statements be justified with such a woeful lack of objective knowledge?
It is necessary to carry out an assessment of the subject's age so that appropriately targeted support can be promptly provided. This is conducted by social workers who use a proforma questionnaire to record the responses of the child. This, combined with the physical appearance of the subject is then used to provide an estimate of the subject's age. This variously takes the form of being an age threshold, for example, the subject is over 14 years and the assignment of a specific age. This age, when approved by the immigration courts is then carried forward into official documents that require a specific date of birth. There appears to be no attempt to indicate the range of ages likely to be appropriate for a given individual.

There are many reasons why a reliable age estimation is necessary. Children who look 'old' for their age are placed in circumstances where they are bullied. Some of these older children, unaccustomed to the social hierarchy of children in UK schools, end up in playground fights as a result of being teased. The issue of age, so important in education, is rarely a problem as so many of the unaccompanied asylum-seeking children have had very little education in their home country so special arrangements for teaching are provided.

The other major reason for estimating age is that adult asylum seekers, aware of the difference in support provided in the UK to subjects over the age of 18 years, claim to be under 18 years old. Those that look like adults are challenged and become 'agedisputed'. Those that continue the dispute are then referred for a judicial review. Until July of 2016 these disputes were decided by a judge who, in reality, had to decide whether or not to believe the asylum seeker or the social workers. DAE has been used in over 650 cases in the UK since 2005. In the Immigration Courts in July 2016 it was determined that age disputed subjects should either accept the social workers age estimation, or submit to a DAE. This was the first formal recognition by the Immigration Courts that DAE could have a pivotal role to play in age disputed asylum seekers.

This column appears to be an attempt to 'forcefully challenge an idea that cannot deliver.' ${ }^{1}$ We are of the view that this and other misleading statements should be challenged, not forcefully (and 'misleadingly') but with the quiet logic of objective knowledge. We also express concern that the article in question has offered no objective evidence to support the views conveyed - strong on opinion, weak on knowledge is the BDA's position on this matter. We would argue that in the current environment of 'evidence-based dentistry' the opinions offered by the BDA are unacceptable and should be withdrawn.

\section{Child protection}

An important issue not considered by the BDA is that of child protection. This is a serious failing on their part; to the point of negligence. Many of the subjects we see are adult looking and claiming to be under 18 years, usually by a suspiciously similar claim across the age disputed subjects, most of whom are male. These adult looking subjects are housed, schooled and generally thrust into the lives of children. This is inappropriate and there are several cases on record where age disputed male asylum seekers have committed sexual assaults on children while masquerading as children themselves. [Editor's note: The authors report that references to these cases cannot be provided at the time of going to press as they are the subject of a judicial embargo.] This issue of child protection was first drawn to the attention of the DARLInG team by one of the authors (VSL) and subsequently disseminated to the dental profession in a letter to the British Dental Journal. ${ }^{13}$ This drew attention to the failure of the Children's Commissioner to highlight this issue. ${ }^{14}$ Similarly, here the BDA have failed to draw attention to this serious issue which is damaging to the well-being of children.

Acknowledgement of this shifts the ethical issue to at least taking account of the potential problem and acknowledging that every measure possible should be taken to protect children from the unwanted and inappropriate attention of young adults. The editor is right to indicate that ethical issues change. An assessment of this damaging social problem must at least consider DAE and when the lack of objective data used in the 'holistic method' is considered this leads very quickly to the acceptance of DAE as it is the most accurate method. The use of DAE will protect children from serious harm. To overlook the needs of children who may be abused is a serious shortfall in terms of due diligence. It is unethical to allow this failure of consideration.

To close, it is necessary to take issue with the heading ' $\mathrm{X}$-rays and X-rated'. The term X-rated refers to pornography. This is a careless and 
misleading use of the term presumably used for rhetorical effect. If not, it is a calumny against the dental surgeons, and others, who strive to help children who need the protection of reliable age estimation. Is this a Freudian slip too far? Or will the BDA withdraw this salacious phrase and print a correction?

1. Husband J. Column. X-Rays and X-rated. Br Dent J In Practice. December 2016; 22: 3.

2. Hockton A. The law of consent to medical treatment. Sweet and Maxwell: London, 2002.

3. The National Archives. The lonising Radiation (Medical Exposure) Regulations 2000. Available at http://www. legislation.gov.uk/uksi/2000/1059/contents/made (accessed June 2017).

4. Upper Tribunal Immigration and Asylum Chamber. 11 November 2016.

5. Yadava M, Lucas V S, Roberts G J. Dental Age Assessment: reference data for children at the 10-year-threshold. Int J Leg Med 2011; 125: 651-657.

6. Chudasama P N, Roberts G J, Lucas V S. Dental Age Assessment (DAA): A study of a Caucasian population at the 13 year threshold. J Forensic Leg Med 2012; 19: 22-28.

7. Lucas VS, McDonald F, Neil M, Roberts G. Dental age estimation: the role of probability estimates at the 10 year threshold. J Forensic Leg Med 2014; 26: 61-64.

8. Lucas VS, Andiappan M, McDonald F, Roberts G. Dental Age Estimation: A test of the reliability of correctly identifying a subject over 18 years of age using the gold standard of chronological age as a comparator. J Forensic Sci 2016; 61: 1238-1242.

9. Liversidge $\mathrm{H} M$, Marsden $\mathrm{PH}$. Estimating age and the likelihood of having attained 18 years of age using mandibular third molars. Br Dent J 2010; 209: E13.

10 Hancocks S. Agreed; but if....? Br Dent J Editorial 2017; 222: 1

11. Roberts G, McDonald F, Lucas V S. Dental Age Estimation: Theory and Practice.In Byard R, Payne-James J (editors) Encyclopaedia of Forensic and Legal Medicine, 2nd Edition. Elsevier, 2015.

12. Demiriian A, Goldstein $H$, Tanner J M. A new system of dental age assessment. Hum Biol 1973; 45: 211-227.

13. Roberts GJ. Ethical Age Assessment. Br Dent J 2009; 206: 581-582.

14. Aynsley-Green A. Unethical age assessment. Br Dent J 2009; 206: 337. 